\title{
Diatomite reinforced chitosan composite membrane as potential scaffold for guided bone regeneration
}

\author{
Sedef Tamburaci ${ }^{a}$, Funda Tihminlioglu ${ }^{\mathrm{b}, *}$ \\ a İzmir Institute of Technology, Graduate Program of Biotechnology and Bioengineering, Gülbahçe Campus, Urla, İzmir, 35430,Turkey \\ b İzmir Institute of Technology, Department of Chemical Engineering, Gülbahçe Campus, Urla, İzmir 35430, Turkey
}

\section{A R T I C L E I N F O}

\section{Article history:}

Received 20 December 2016

Received in revised form 2 May 2017

Accepted 13 May 2017

Available online 20 May 2017

\section{Keywords:}

Composite

Diatomite

Chitosan membrane

Biomaterial

Bone

Natural silica

\begin{abstract}
A B S T R A C T
In this study, natural silica source, diatomite, incorporated novel chitosan based composite membranes were fabricated and characterized for bone tissue engineering applications as possible bone regeneration membrane. The effect of diatomite loading on the mechanical, morphological, chemical, thermal and surface properties, wettability and in vitro cytotoxicity and cell proliferation on of composite membranes were investigated and observed by tensile test, atomic force microscopy (AFM), Fourier transform infrared spectroscopy (FTIR), thermal gravimetric analysis (TGA), protein adsorption assay, air/water contact angle analysis and WST-1 respectively. Swelling studies were also performed by water absorption capacity determination. Results showed that incorporation of diatomite to the chitosan matrix increased the surface roughness, swelling capacity and tensile modulus of membranes. An increase of about 52\% in Young's modulus was achieved for $10 \mathrm{wt} \%$ diatomite composite membranes compared with chitosan membranes. High cell viability results were obtained with indirect extraction method. Besides, in vitro cell proliferation and ALP activity results showed that diatom incorporation significantly increased the ALP activity of Saos- 2 cells cultured on chitosan membranes. The novel composite membranes prepared in the present study with tunable properties can be considered as a potential candidate as a scaffold in view of its enhanced physical \& chemical properties as well as biological activities for bone tissue engineering applications.
\end{abstract}

(C) 2017 Elsevier B.V. All rights reserved.

\section{Introduction}

Silicon is one of the trace elements present in nature as silicates and silica (hydrated silicon dioxide), known to be essential in biological processes for the production of structural materials and it is an essential element in connective tissue, especially in bone and cartilage for organic matrix formation which is composed of collagen and glycosaminoglycan. Silica offers many advantages over other inorganic materials, being biocompatible, thermally and mechanically stable, resistant to microbial attack and optically transparent $[1,2,3]$. Silicate nanoparticles have been extensively used to improve the mechanical properties of synthetic and natural polymers by showing significant improvements in structure, modulus, strength and toughness that cannot be achieved by using the polymer alone. Thus, silicate nanoparticles are commonly used for biomedical applications as reinforcements [2]. Besides, there have been a number of studies that revealed the biological functions of silica particles supporting bone cell adhesion, bone tissue formation and biomineralization. High Si contents have been detected in early stages of bone matrix calcification, and aqueous $\mathrm{Si}$ induced precipitation

\footnotetext{
* Corresponding author.

E-mail address: fundatihminlioglu@iyte.edu.tr (F. Tihminlioglu).
}

of hydroxyapatite (HAp) in bone tissue by enhancing the bone in growth as a calcifying agent. Thus, silica incorporation is considered to be a potential method improve mineralization and the bioactivity of HAp in bone regeneration [3,4,5]. Additionally, in vitro studies showed that silica particles effected bioactivity of scaffolds and increasing silicate concentration favored cell proliferation, enhanced alkaline phosphatase activity and the expression of bone-specific genes of cells cultured on scaffolds. Studies showed that silica induced $\mathrm{CaO}$ accumulation on the surface and showed apatite forming ability in SBF which is an essential step for bone tissue formation and mineralization process $[1,2,6,7,8,9,10]$.

Diatomaceous earth, or diatomite, is a natural silica material consisting of an accumulation of skeletons formed as a protective covering by diatoms which are non-motile, unicellular eukaryotic photosynthetic microalgae. Diatoms have unique physical characteristics, such as high permeability due to their numerous microscopic well-arranged pores and channels on the outer or inner surfaces and sieve pores being approximately $40 \mathrm{~nm}$ for exchanging nutrients and gases. This porous structure results high specific surface area possibly reaching $200 \mathrm{~m}^{2} / \mathrm{g}$, high adsorption capacity and low density [11]. Besides, it has relatively low price and high abundance cause to be used as reinforcing fillers, filter aids, abrasives, insulating materials, membranes 
and biocatalytic proteins and cells $[12,13,14,15]$. Diatomite particles are negatively charged, and possesses strong attractability for positively charged species in aqueous solutions [16]. The silica surface contains silanol groups which are active and tend to react with many polar organic compounds and various functional groups $[17,18]$. The extraordinary 3D biosilica structure of the diatoms makes them ideal candidates to be used as multifunctional scaffolds with the presence of free hydroxyl groups on the large surface area of the frustules which enable easy functionalization with biological or chemical moieties [19]. These frustules or the processing $\mathrm{SiO}_{2}$ nano powders from diatom frustules can be used to reinforce biomaterials and for drug delivery applications with with micro and nanoscale porosity, non-toxic structure [20,21]. Only a few studies have addressed the the potential engineering and biomedical applications of diatom frustules as natural silica particles. Lopez-Alvarez et al. investigated the influence of silicon substituted hydroxyapatite coatings on osteoblast-like SaOs-2 cell line by using diatomaceous earth as silicon source. In vitro studies indicated that Si-HAp coating from significantly favored osteoblast proliferation and activity in comparison to the Si-HAp coating from synthetic silica [22]. Hertz et al. prepared porous $\mathrm{SiO}_{2}$ and $\mathrm{SiO}_{2} / \mathrm{TiO}_{2}$ monoliths from flux calcined diatomaceous earth and found that samples containing only $\mathrm{SiO}_{2}$ were proved to be biocompatible for bone tissue engineering [23]. Le et al. studied the potential of diatom particles as silicon-donor materials for bone tissue engineering applications and purified diatom-derived microparticles (MPs) and nanoparticles (NPs) showed limited or no cytotoxic effect [4].

To our knowledge, there is no study related to the diatom incorporated scaffolds for tissue engineering applications. As a well-known natural polymer, chitosan has been widely used for bone tissue engineering applications due to its good biocompatibility with its amino and hydroxyl groups, broad antimicrobial activity and biodegradability. Besides, its structural similarity to glycosaminoglycans promotes osteoblast adhesion, growth and mineral rich matrix deposition [24, $25,26,27]$. However, it has some limitations such as low tensile strength and modulus range when compared with natural bone. Common approach to overcome this mechanical incompatibility with bone is to use an inorganic reinforcement agents in the polymer matrix. Therefore, the present study aims to combine the useful biomaterial properties of both chitosan and diatomite as a natural silica as biocomposite organic/inorganic biomaterials for bone tissue engineering applications and to investigate the effect of diatomite loading on the mechanical, chemical, and swelling properties, morphological and surface wettability of composites as well as in vitro cytotoxicity and cellular activities including cell proliferation and cell differentiation.

\section{Material and method}

Chitosan low molecular weight powder (50,000-190,000 Da), was purchased from Sigma-Aldrich and used for preparation of composite membranes and Diatomite (Celpure ${ }^{\circledR} \mathrm{P} 65, \mathrm{SiO}_{2}, 98 \%$, Sigma-Aldrich) was used as natural silica source for reinforcement. Acetic acid (analytical grade, Sigma-Aldrich) was used as solvent preparation. WST-1 ready to use cell proliferation reagent (BioVision Inc.) and StemTAG ALP Assay kit (Cell Biolabs Inc.) was used for in vitro cell culture assays. DAPI (Cell Signaling Technology) and Alexa Fluor 488 (Thermo Fisher Scientific, Molecular Probes) were used for fluorescence staining.

\subsection{Preparation of chitosan/diatomite composite membranes}

Chitosan/diatomite composite membranes were prepared by solvent casting method. Chitosan solution ( $1 \mathrm{wt} \%$ ) was prepared by dissolving chitosan in $1 \% \mathrm{v} / \mathrm{v}$ acetic acid and diatomite was dispersed in acetic acid for $24 \mathrm{~h}$, separately and then mixed solution was homogenized with sonication method (Misonix Ultrasonic Liquid Processor; $30 \mathrm{~min}, 15^{\circ} \mathrm{C}, 35$ Amplitude). Chitosan/diatomite composite dispersion was poured into petri dishes and dried at ambient condition. Finally, samples were dried in vacuum oven at $37^{\circ} \mathrm{C}$. Membrane thickness was measured by micrometer caliper and found in the range of 70-85 $\mu \mathrm{m}$.

\subsection{Characterization of chitosan/diatomite membranes}

\subsubsection{Surface characterization of chitosan/diatomite composite membranes}

2.2.1.1. AFM analysis. Atomic force microscopy (AFM) imaging was performed by using Nanoscope SPM (Digital Instruments Inc., USA). Point probe cantilever tip was used in contact mode by the accompanying software to determine the surface morphology and roughness of membrane surfaces. The roughness parameters of each sample was evaluated on three scanned areas of $5 \mu \mathrm{m} \times 5 \mu \mathrm{m}$ each.

2.2.1.2. SEM analysis. The surface morphology on membranes and diatomite polymer matrix interaction from cross-sections were investigated by using Quanta FEG scanning electron microscopy (FEI, Thermo Fisher Scientific). Samples were coated with a thin layer of gold with a current of $15 \mathrm{~mA}$ under vacuum before analysis.

2.2.1.3. Surface wettability. The static water contact angles of pure chitosan and all composite membranes were measured with Attension Theta Lite optical tensiometer. Samples ( $1 \mathrm{~cm}$ width and $5 \mathrm{~cm}$ length) for each group were prepared before the measurement. Ultrapure water was used as liquid phase and drop size was set to $6 \mu$ l. All data presented were determined as the mean values of five independent measurements.

2.2.1.4. Protein adsorption. Chitosan/POSS composite membranes were incubated in protein solution in order to determine the proteins adsorption on surface. Samples were treated by PBS for 30 min before the incubation process with protein solution. Bovine serum albumin (BSA) $(0.1 \%$ $w / v$ ) was used as model protein. The sample specimens were incubated at $37^{\circ} \mathrm{C}$ for $24 \mathrm{~h}$, and $48 \mathrm{~h}$. The amount of adsorbed proteins on membranes was determined by a commercial protein assay kit, BCA (Pierce, Rockford, IL), using bovine serum albumin (BSA) as standards [28].

\subsubsection{Chemical and thermal characterization}

2.2.2.1. Fourier transform infrared spectroscopy (FTIR). Alterations on bond structures of composite membranes were determined by ATRFTIR spectroscopy. Analysis was performed with Shimadzu FTIR 8400 S Fourier transform infrared spectrophotometer. All spectra were obtained from 400 to $4000 \mathrm{~cm}^{-1}$ at $4 \mathrm{~cm}^{-1}$ resolution.

2.2.2.2. Thermal gravimetric analysis (TGA). Thermogravimetric analysis (Perkin Elmer Diomand TG/DTA) was used to evaluate the thermal stability of the composites. Analyses were carried out in a nitrogen atmosphere from $30^{\circ} \mathrm{C}$ to $650{ }^{\circ} \mathrm{C}$ at a heating rate of $10^{\circ} \mathrm{C} / \mathrm{min}$.

\subsubsection{Mechanical characterization of chitosan/diatomite composite membranes}

Mechanical properties of chitosan/silica composite membranes were measured by tensile testing according to the ASTM D882-02 Standard. Before the measurement, for each group five samples $(1 \mathrm{~cm}$ width and $5 \mathrm{~cm}$ length) were prepared. Thickness of tested membranes was measured with an electronic digital micrometer (293-821. Mitutoyo) with $1 \mu \mathrm{m}$ sensitivity by taking the average of four different points. TA XT Plus Texture Analyzer equipped with a $5 \mathrm{kgf}$ load cell was used for determination of stress-strain data of the samples. Initial gauge length and cross-head speed were set as $100 \mathrm{~mm}$ and $10 \mathrm{~mm} / \mathrm{min}$. Ultimate tensile strength, strain at break, and Young's modulus of the samples were calculated from strain-stress data. The resulting data were reported as the average of at least 5 samples. 

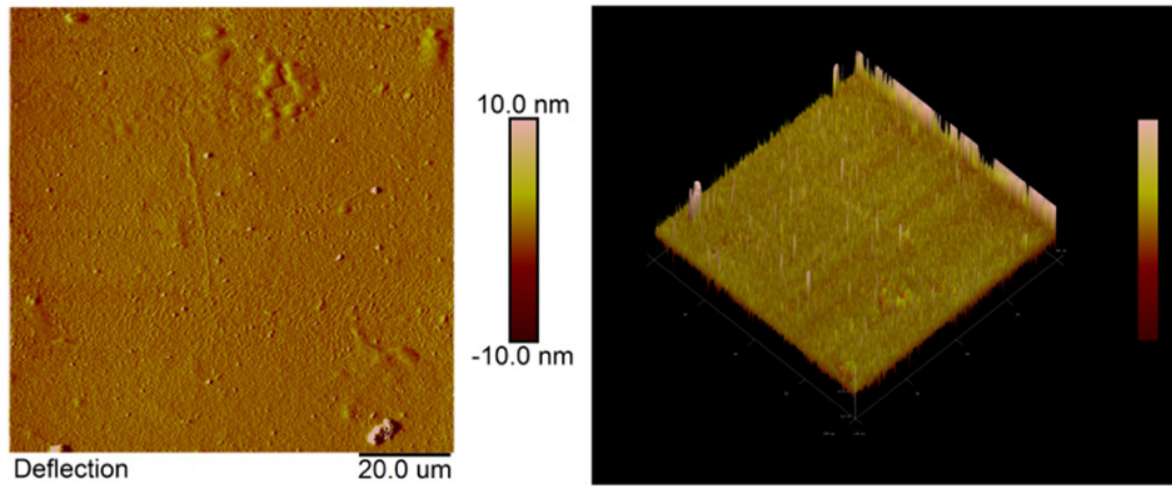

Fig. 1. AFM images of pure chitosan membrane. Phase (left) and topography (right).

\subsubsection{Water absorption capacity of chitosan/diatomite composite} membranes

Swelling test is performed in order to obtain swelling behavior of chitosan/diatomite composite membranes in implanted tissue. Briefly, dry samples were firstly weighted and noted as $\mathrm{W}_{\mathrm{d}}$ samples. Then, they were swollen in $1 \times \mathrm{PBS}$ (phosphate buffered saline) (PBS) at $37{ }^{\circ} \mathrm{C}$ for $1 \mathrm{~h}, 24 \mathrm{~h}$ and $48 \mathrm{~h}$ periods. Following the incubation, they were removed and extra solution on the surface was removed by pressing on filter paper. Wet samples $\left(\mathrm{W}_{\mathrm{w}}\right)$ were weighted. Swelling ratio (SR) (or degree of swelling) was then determined with Eq. 1 [29]. The results were given as mean $\mathrm{SR} \pm$ standard deviation.

$\mathrm{SR}=\frac{\mathrm{Ww}-\mathrm{Wd}}{\mathrm{Wd}}$

\subsection{In vitro studies}

\subsubsection{Cytotoxicity}

Cytotoxicity of composite membranes was evaluated by the WST-1 [4-3-(4-Iodophenyl)-2-(4-Nitrophenyl)-2H-5-Tetrazolio]-1,3-Benzene Disulfonate] colorimetric assay based on the conversion of stable tetrazolium to a soluble formazan by a complex cellular mechanism that occurs primarily at the cell surface [30]. This bioreduction is largely dependent on the glycolytic production of $\mathrm{NAD}(\mathrm{P}) \mathrm{H}$ in viable cells.

In vitro cytotoxicity of chitosan/diatomite composite membranes on 3T3 fibroblast and Saos-2 osteosarcoma cell lines was determined by indirect extraction method (ISO 10993 Standard). Cell lines were maintained in DMEM supplemented with $2 \mathrm{mM}$ L-glutamine, 10\% fetal bovine serum, $100 \mu \mathrm{g} / \mathrm{ml}$ streptomycin and $100 \mathrm{U} / \mathrm{ml}$ penicillin in an atmosphere of $5 \% \mathrm{CO}_{2}$ at $37{ }^{\circ} \mathrm{C}$. Subcultivation was performed every $48 \mathrm{~h}$.
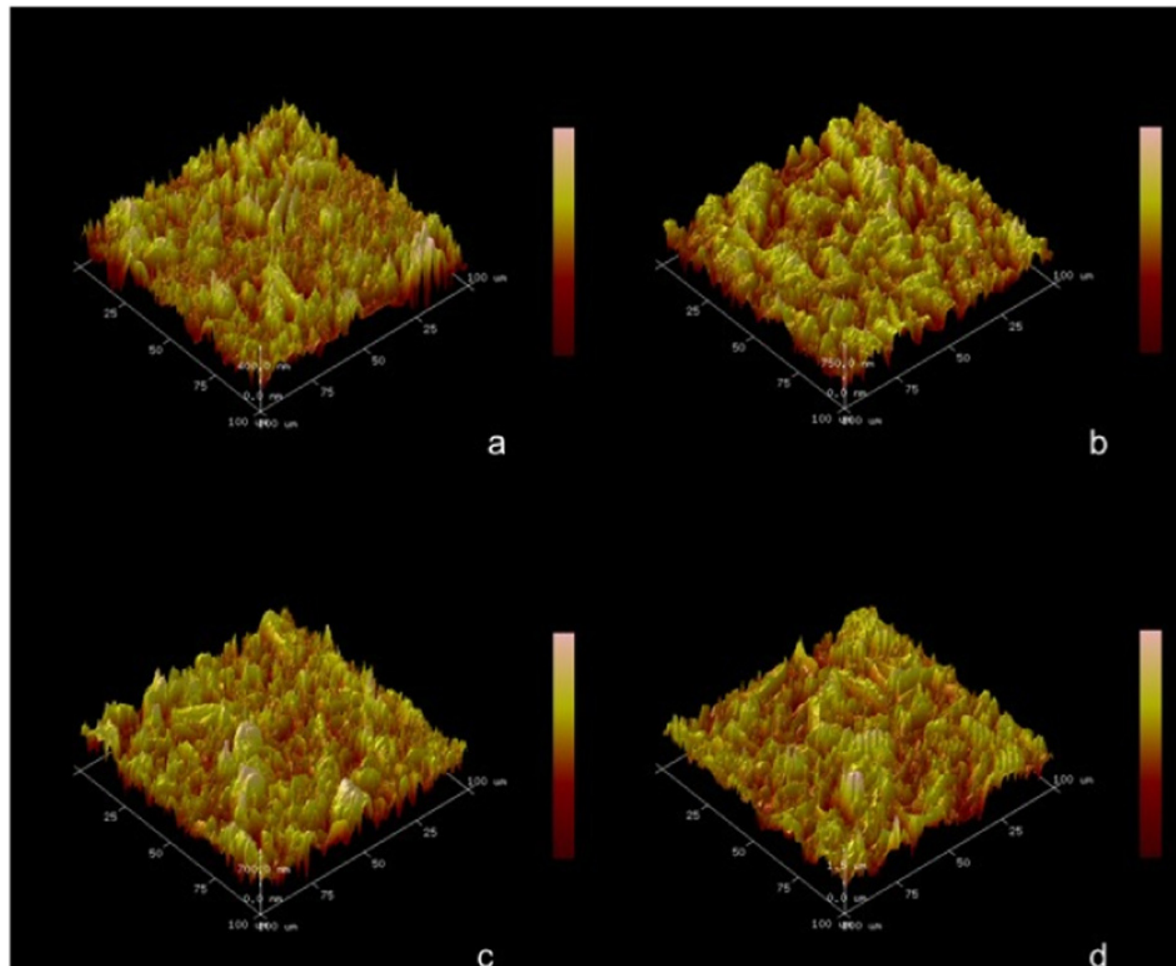

b

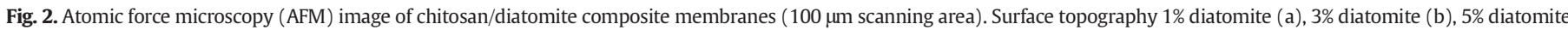
(c) and $10 \%$ diatomite (d) content respectively. Surface roughness is induced by agglomeration of diatomite particles on the surface. 

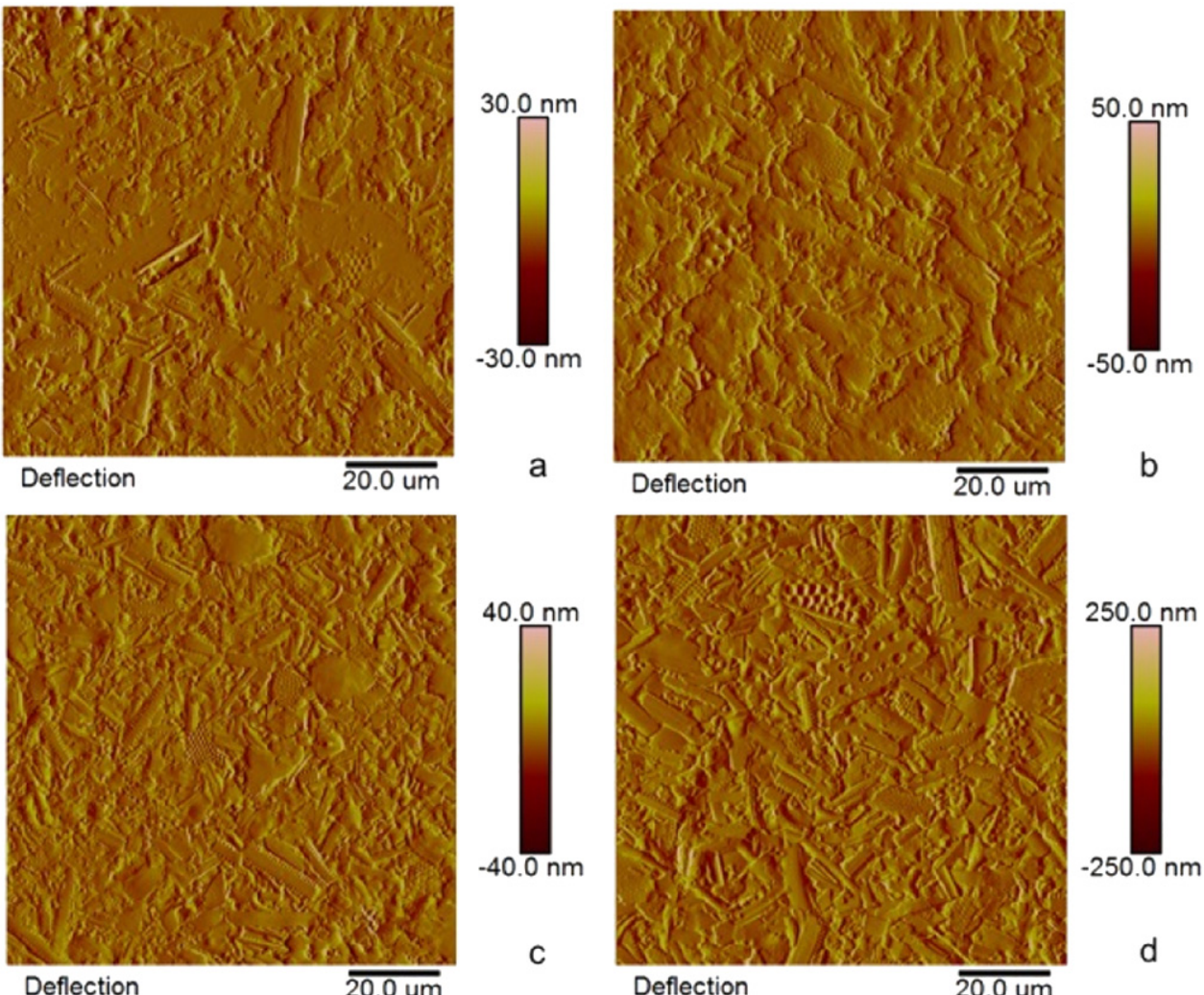

b

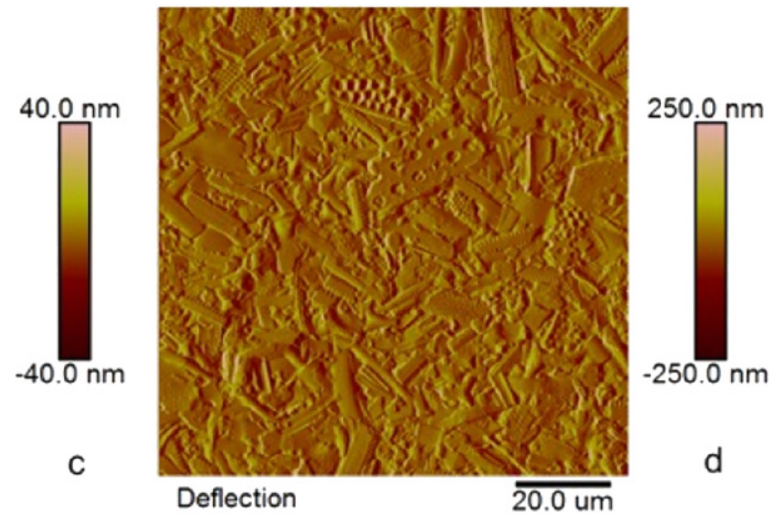

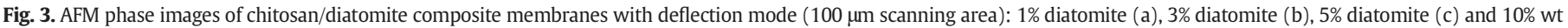
diatomite $(\mathrm{d})$

Experiments were performed in triplicate. Optical density determined at $440 \mathrm{~nm}$ was normalized to cell viability \%.

In vitro cell proliferation on chitosan/diatomite composite membranes was also assessed by WST-1 assay. Specimens were sterilized with $70 \%$ ethanol for $24 \mathrm{~h}$, washed with $1 \times$ PBS and conditioned with cell culture medium for $2 \mathrm{~h}$ before cell seeding. 50000cell/well were seeded on membranes $(1 \mathrm{x} 1 \mathrm{~cm})$ with $20 \mu$ inoculation volume. Finally, Saos- 2 cells cultured on samples were incubated at $37{ }^{\circ} \mathrm{C} / 5 \% \mathrm{CO}_{2}$ with $1 \mathrm{ml}$ DMEM medium. 1 Culture medium was changed twice a week during the proliferation.

\subsubsection{Cell attachment and proliferation on membranes}

Cell proliferation on membranes was determined with WST-1 viability assay for different incubation times (1,3,5,7,10 and 14 day). Cell spreading and proliferation on membrane surface was determined by fluorescence microscopy with dapi/phalloidin staining.

\subsubsection{Alkaline phosphatase activity}

Alkaline phosphatase activity of Saos- 2 cells cultured on membranes

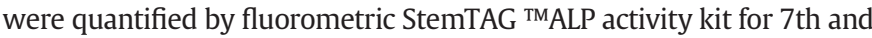
2th day incubation periods.

\subsection{Statisctical analysis}

All experiments were repeated thrice and samples were evaluated in triplicate. The experimental data is expressed as the standard deviation of the mean (SEM). Statistical analysis of mechanic test and swelling data were carried out using One-way ANOVA with Tukey's multiple comparison test $(p<0.05)$. Statistical analyses of in vitro studies were carried out using two way ANOVA with Tukey's multiple comparison test $(p<0.05)$.

\section{Results and discussion}

\subsection{Surface properties}

\subsubsection{AFM analysis}

The surface characteristics of a biomaterial can effect the cell behavior at different levels such as growth, differentiation and apoptosis. Cytoskeletal organization of cells on material surface is generally determined by cell-surface interaction.Therefore, micro and nanotopography on a biomaterial surface is an important factor for cell proliferation [31]. The surface properties and adsorption capacity of diatomite are highly governed by the presence of water and structurally connected to the crystal mesh of the diatomite, forming active hydroxyl groups [19]. The interaction between the diatomite filler and the polymer matrix specify reinforcement level in composite. Thus, optimum performance is obtained when the reinforcement is uniformly dispersed in the structure and interact strongly with the organic matrix. In order to observe this dispersion and interaction of filler with the polymer matrix, AFM analysis was performed with contact mode. Besides the effect of highly porous diatomite filler particles on surface roughness was determined by AFM analysis. Figs. 1-3 show the surface topography and phase images of chitosan and chitosan composites, respectively. As it can be seen in Fig. 1 and Fig. 2, the AFM images

Table 1

Surface Roughness of pure chitosan and chitosan/diatomite composite membranes $\pm S D$ for three measurements.

\begin{tabular}{ccc}
\hline Membrane Groups & Roughness $(\mathrm{Rq})(\mathrm{nm})$ & Surface Area Difference $\%$ \\
\hline Chitosan & $2.38 \pm 0.12$ & 0.00 \\
1\% Diatomite & $114.7 \pm 7.54$ & $1.3 \pm 0.21$ \\
3\% Diatomite & $265 \pm 46.07$ & $3.8 \pm 0.24$ \\
5\% Diatomite & $257.3 \pm 23.10$ & $4.4 \pm 0.04$ \\
10\% Diatomite & $380.7 \pm 35.74$ & $10.9 \pm 1.45$ \\
\hline
\end{tabular}




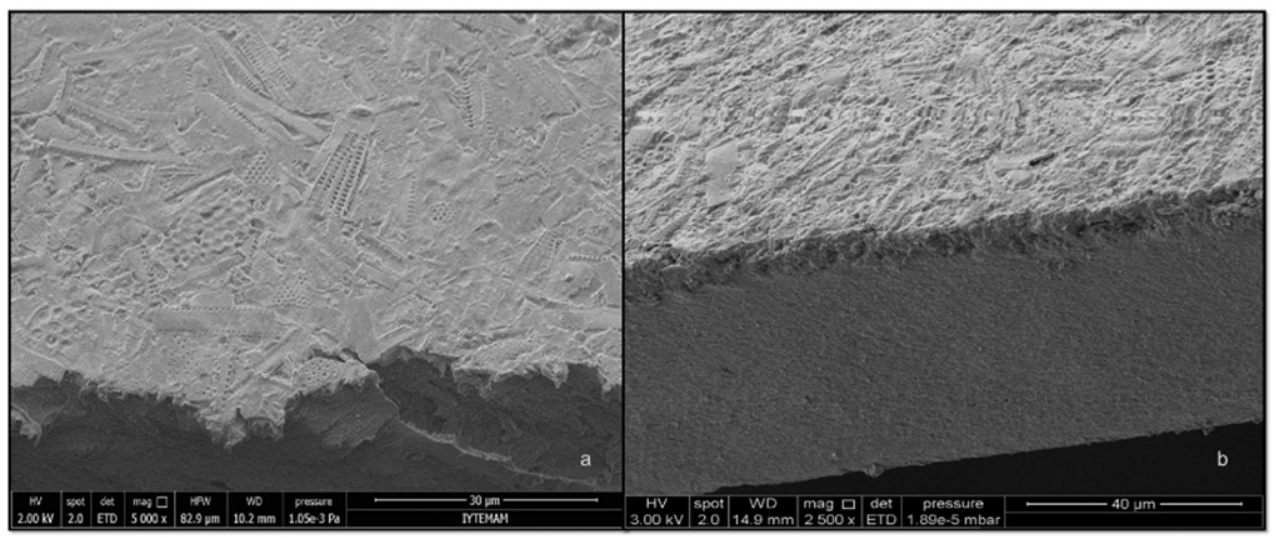

Fig. 4. SEM images of chitosan-diatomite composite membrane surfaces: chitosan-1\%diatomite (a); chitosan- $10 \%$ diatomite (b).

show differences in surface properties of composite membranes compared to chitosan membrane. The surface was smooth for chitosan membranes, showing negligible topographic features. On the other hand, the surface morphology of composites differs with increasing diatomite concentration (Fig. 2 and Fig. 3). When compared with pure chitosan membrane, diatomite filler incorporation increased the surface

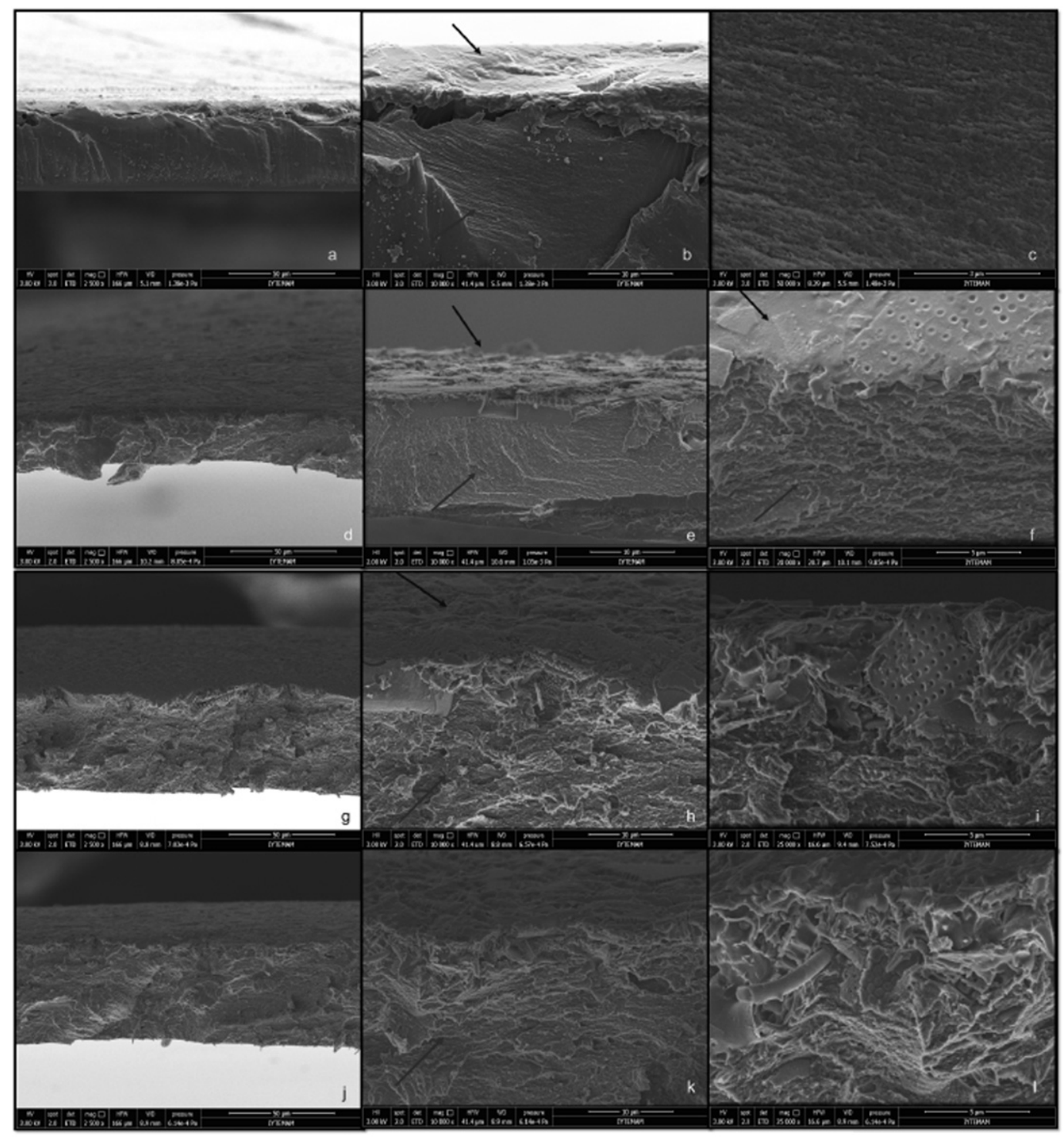

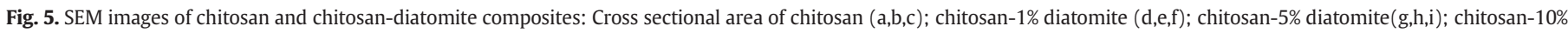
diatomite (j,k,l) with 50,10 and $5 \mu \mathrm{m}$ scale. Black arrows show the upper layer and red arrows depict cross-sectional part of membranes. 
roughness, a significant factor for cell adhesion and proliferation on material surface (Fig. 2). The deflection phase images showed the diatomite particles embedded and dispersed in polymer matrix (Fig. 3). The surface roughness data of chitosan and chitosan/diatomite composite membranes were listed in Table 1.

AFM phase images of chitosan/diatomite composite membranes (Fig. 3) showed that diatomite frustules with various morphology distributed on polymer surface inducing roughness. Besides, uniform distributions were observed on surface with increasing diatomite content (5-10\%). AFM analysis of cell skeleton of diatom in the literature showed that outer layer of the skeleton showed a granular nanostructure composed of 100-200 nm spherically shaped fused silica particles and a surface topography with holes with a 200-300 nm size range [32]. Similarly, diatom frustules distributed on composites showed a pore size range of $0.3 \mu \mathrm{m}$ to $5 \mu \mathrm{m}$ in their structure (Fig. 3). Diatomite frustules with diverse porous structures showed higher roughness on chitosan surface.

\subsubsection{SEM analysis}

Scanning electron microghraphs showed that diatomite particles were embedded on the surface, upper layer of the membrane. Fig. 4 indicated that diatomite particles uniformly dispersed on surface with low concentration (1\%) when compared to high concentration (10\%). This could be due to the particle-particle interactions of diatomite with each other and start to agglomerate on the surface.

Cross-sectional areas of the chitosan and composite membranes were observed with SEM analysis and depicted in Fig. 5. As seen in Fig. 5, diatomite particles were only dispersed and embedded on the upper surface of the membrane and particles can be seen more easily on the surface as the diatomite loading increases. Thus, chitosan-diatomite membranes act as a barrier membrane consisting of two different layers. Upper layer shows a favorable structure for osteoblast attachment and proliferation (depicted with black arrow) and sublayer shows a uniform, dense structure to act as a barrier for fibroblast migration to the bone defect site.

\subsubsection{Surface wettability}

The hydrophilicity obtained on the surface of the material is an important factor that determines the affinity for cell adhesion. Generally, hydrophilic surface is considered to be appropriate for cell proliferation [33]. Protein adhesion which initiates the cell-surface interaction, is limited on highly hydrophobic and hydrophilic surfaces. Extracellular matrix protein adsorption is better on highly hydrophilic surface. However, cell-cell interaction decreases and this prevents monolayer formation due to the stronger substrate-cell interaction. Thus, moderately wettable surfaces induce cell adhesion and proliferation [34,35, 36]. Static air-water contact angle data of composite membranes were measured in order to determine the hydrophilicity (Table 2). Diatomite particles dispersed on the upper surface of the membrane with increasing content did not have a major effect on the surface wettability. Incorporation of diatomite particles into chitosan matrix slightly decreased the contact angle up to $3 \%(\mathrm{w} / \mathrm{w})$ diatomite. Slight increase in contact angle was observed for $10 \%$ diatomite incorporated samples, due to the diatomite agglomerations on surface. However, all composite membranes showed moderately hydrophilic surface properties with contact

Table 2

Water contact angle of chitosan and composite membranes. The data of water contact angle was shown as the mean \pm SD for three measurements.

\begin{tabular}{ll}
\hline Membrane Groups & Static air-water Contact Angle $\left(^{\circ}\right)$ \\
\hline Chitosan & $77.9 \pm 5.6$ \\
1\% Diatomite & $73.7 \pm 1.72$ \\
3\% Diatomite & $73.5 \pm 1.71$ \\
$5 \%$ Diatomite & $77 \pm 2.5$ \\
10\% Diatomite & $79.1 \pm 0.63$ \\
\hline
\end{tabular}

angle data below $90^{\circ}$. Thus, composite membranes showed appropriate surface properties for protein and cell adhesion.

\subsubsection{Protein adsorption}

The cell-substrate interaction the major factor during cell adhesion. Protein adsorption on surface is a major process for cell-matrix interaction via regulation of cell migration, spreading and proliferation. When biomaterial contacts with a fluid containing soluble proteins (blood, body fluid or cell culture media), protein adsorption on material surface takes place. Thus, cell do not contact the molecular structure of biomaterial when seeded. They contact and interact with the adsorbed protein layer [36,37]. In this study, protein adsorption on membranes was determined by using BCA colorimetric protein assay kit for $24 \mathrm{~h}$. Results showed that diatomite incorporation enhanced protein adsorption on the surface of chitosan membranes and membranes adsorbed protein gradually with time except $10 \%$ wt diatomite loaded samples This may arises due to the slight increase in contact angle on surface. Maximum protein adsorption was observed as $194.5 \mu \mathrm{g} / \mathrm{ml}$ with $5 \%$ wt diatomite for $24 \mathrm{~h}$ (Fig. 6)

\subsection{Chemical and thermal properties}

\subsubsection{FTIR analysis}

Chitosan/diatomite composite membranes were subjected to FTIR spectroscopy to observe the differences in bond structure with diatomite incorporation to polymer matrix. The infrared spectra of diatomite powder and chitosan/diatomite composites are presented in Fig. 7. Similar to synthetic amorphous silicas, the reactivity of diatomite is identified with the presence of primary reactive sites hydroxyl groups on their surface [38]. Khraisheh et al. clarified the importance of the various functional groups, available on the surface of diatom, on the mechanism of adsorption. Diatomite surface has $\mathrm{OH}$ groups and oxygen bridges which act as adsorption sites on its surface. The adsorption site groups are free silanol $(-\mathrm{SiOH})$, geminal free silanol $\left(\mathrm{Si}(\mathrm{OH})_{2}\right), \mathrm{OH}$ groups act as adsorption sites and bound through the hydrogen bond. Diatomite also has siloxane groups (-Si-O-Si-bridges) with oxygen atoms on its surface [18]. Basic characteristic peaks of chitosan $\mathrm{NH}_{2}$ bending at $1600-1635 \mathrm{~cm}^{1}, \mathrm{~N}-\mathrm{H}$ bending at $1580 \mathrm{~cm}^{-1}$ and $\mathrm{NH}$ streching at $3000-2500 \mathrm{~cm}^{-1}$ were seen in FTIR spectra. Chitosan showed a band appearing in the spectrum were due to stretching vibrations of $\mathrm{OH}$ groups in the range from of $3547-2850 \mathrm{~cm}^{-1}$. FTIR analysis of chitosan/diatom composite membranes showed $\mathrm{Si}-\mathrm{O}-\mathrm{Si}$ bond peaks at $460 \mathrm{~cm}^{-1}$ and $\mathrm{Si}-\mathrm{O}$ bond peaks at 470 and $1050 \mathrm{~cm}^{-1}$ when compared with pure chitosan film due to the diatomite incorporation. Diatomite particles show two characteristic absorptions at $1050 \mathrm{~cm}^{-1}$ and $470 \mathrm{~cm}^{-1}$, which are assigned to Si-O-Si stretching and bending vibration, respectively. The intensity of $\mathrm{Si}-\mathrm{O}-\mathrm{Si}$ and $\mathrm{Si}-\mathrm{O}$ peaks increased with diatom content in polymer.

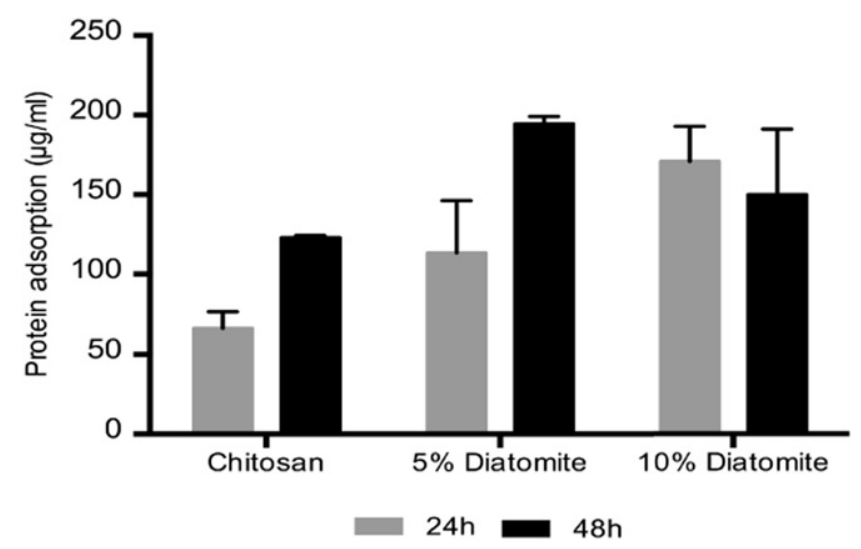

Fig. 6. Adsorption of BSA on chitosan/diatomite composite membranes for $24 \mathrm{~h}$ and $48 \mathrm{~h}$ periods. 


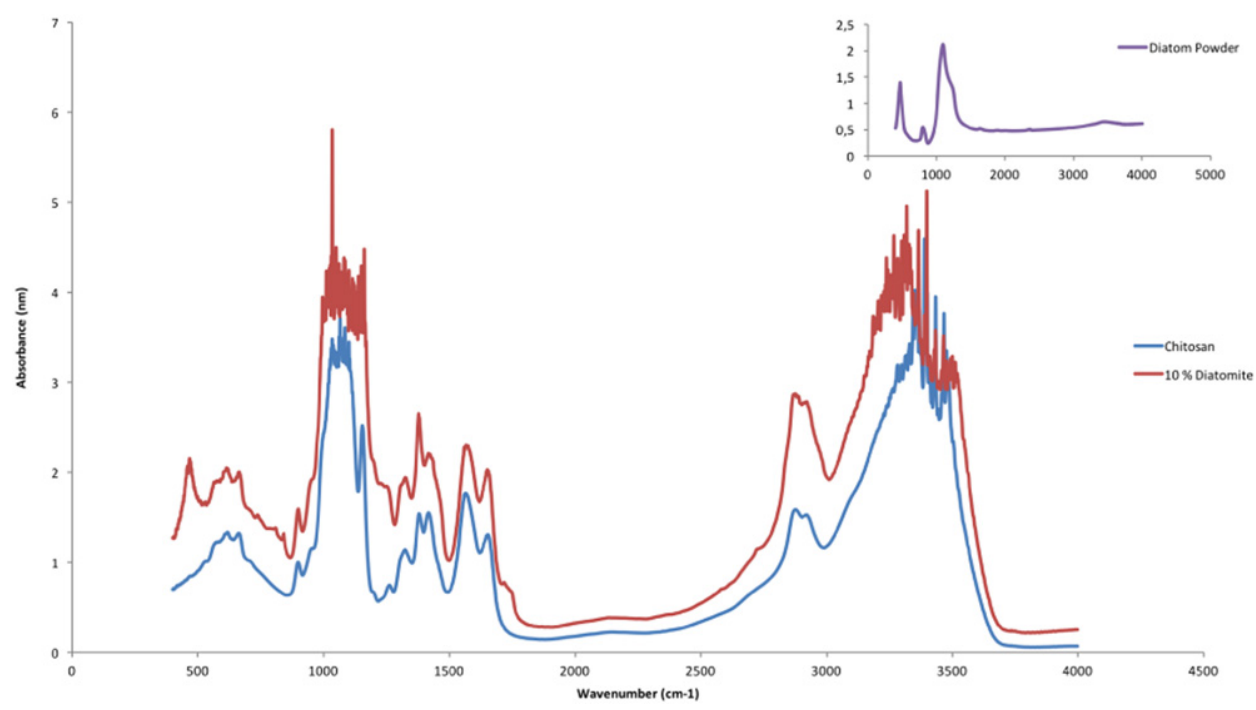

Fig. 7. FTIR spectra of diatomite powder and chitosan/diatomite composite membranes.

\subsubsection{Thermal gravimetric analysis}

To determine the thermal decomposition behavior and study the effect of silica reinforcement on thermal stability of the chitosan-diatomite nanocomposites, thermogravimetric analysis (TGA) was carried out. The thermal stability of chitosan/diatomite composites depends on diatomite-polymer surface interactions and the amount of diatomite particles. Fig. 8 shows the TGA thermograms of the chitosan and the composite membranes with different diatomite filler content. The results indicate that composite membranes exhibited similar TG trends. Initial weight loss $\%$ was observed for all groups at $100^{\circ} \mathrm{C}$, due to vaporization of water from the samples. The second weight loss \% occurred between $300{ }^{\circ} \mathrm{C}$ and $315^{\circ} \mathrm{C}$ related to thermal degradation of polymer structure (depolymerization of chitosan). The presence of diatomite did not affect the degradation mechanism as well as of degradation temperature of chitosan composites. Mendioroz et al. revealed that thermal degredation process of diatomites consisting of generally three main steps. The first main step, between $25^{\circ} \mathrm{C}$ and $100 \pm 10^{\circ} \mathrm{C}$ is related with mechanically trapped or absorbed water and degradation quantity depends on the particle size and surface area of the samples [39]. Chitosan shows slower weight loss in the region between $160{ }^{\circ} \mathrm{C}$ and $270{ }^{\circ} \mathrm{C}$ due to the decomposition of low molecular weight species. Thermal decomposition of chitosan is observed in the region between $170{ }^{\circ} \mathrm{C}$ and $450{ }^{\circ} \mathrm{C}$ regarding to the complex dehydration of the saccharide rings,

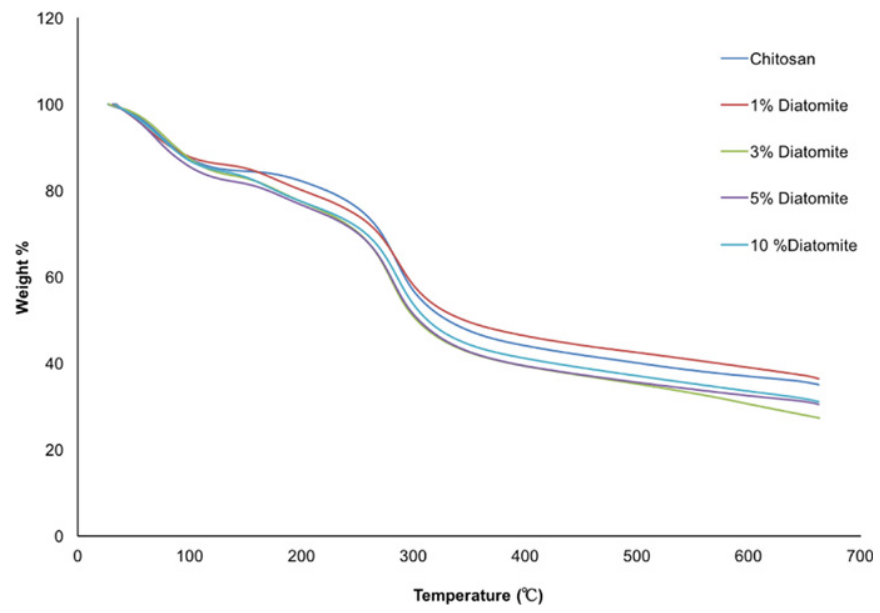

Fig. 8. TGA thermogram of chitosan/diatomite composite membranes under nitrogen environment. depolymerization, and decomposition of the acetylated and deacetylated units of the polymer [40]. Due to structural water loss, the second degradation step, appears between 100 and $350 \pm 20^{\circ} \mathrm{C}$, related with the nature of the opaline phase which is the main component of diatomite and a highly disordered, nearly amorphous, natural hydrous silica. The third step, occurs at $750 \pm 80^{\circ} \mathrm{C}$, due to the decomposition of alkali metal and alkaline earth metal carbonates in diatomite. Their nature and concentration in diatomite structure determine the differences in decomposition temperature of the samples [39]. Our results show that thermal decomposition temperature is not effected with diatomite incorporation.

\subsection{Mechanical properties}

Inorganic reinforcements in polymer matrix is generally used for improving the mechanical strength and modulus of structure. This improving effect of reinforcement depends on size, shape, and dispersion of particles in polymer matrix [41]. Tension test of membranes were performed according to ASTM D882-02 standard. The effect of diatomite addition on the mechanical properties of the composite membranes were investigated. The neat chitosan membrane had a Young's modulus of 13,5 MPa whereas. Young's moduli of the composite membranes increased significantly with increasing amount of diatomite particles attaining a maximum value of $25,9 \pm 0,77 \mathrm{MPa}$ at $10 \%$ diatomite( $w / w)$ (Fig. 9). An increase of about $52 \%$ in tensile modulus was obtained when compared with chitosan membrane.

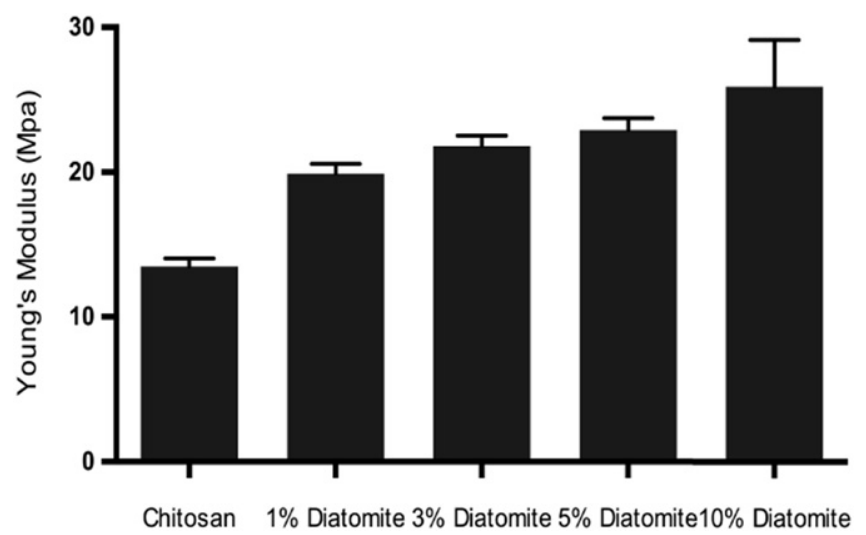

Fig. 9. Young's moduli of chitosan/diatomite composites with increasing diatomite content. 


\subsection{Swelling properties}

Water absorption capacity of a biomaterial is an important factor in order to absorb body fluids at the defect site. Swelling \% of chitosan and composite membranes were determined for $1 \mathrm{~h}$ and $24 \mathrm{~h}$ incubation periods (Table 3). Swelling study results indicated that diatomite filler enhanced the swelling capacity of chitosan. 5\% diatomite incorporated composite membranes showed the highest swelling ratio for both $1 \mathrm{~h}$ and $24 \mathrm{~h}$. Similarly in literature, silica loading in chitin and chitosan polymers increased the swelling properties of the material positively $[7,42]$.

Increasing diatomite concentrations enhanced the water absorption capacity of composite membranes due to the hydrophilic nature of diatomite particles. However at 10\% diatomite concentration swelling capacity of membranes decreased. This may arise from microstructural alterations due to the non-uniform dispersion of diatomite particles on membrane surface.

\subsection{In vitro studies}

\subsubsection{Cytotoxicity of chitosan/diatomite membranes}

In vitro cytotoxicity of composite membranes was evaluated by using indirect extraction method (ISO 10993). Composite membranes were extracted for $24 \mathrm{~h}$ in culture medium at $37{ }^{\circ} \mathrm{C}$ according to ISO 10993 standards. Absorbance values obtained with WST 1 assay are normalized to control group as cell viability \%. Results indicated that chitosan/diatomite membrane extracts did not show any cytotoxic effect on 3T3 fibroblast and Saos-2 cells. High cell viability \% results were obtained for all incubation periods. Increasing diatomite content did not show toxic effect on cells. (Fig. 10). Cell viability results showed that, diatomite particles had a proliferative effect on Saos-2 cells when compared to chitosan control group. For Saos-2 cells, the cell viability results of diatomite loaded groups were found to be statistically significant for $72 \mathrm{~h}$ when compared to chitosan membrane.

\subsubsection{Cell attachment and proliferation}

Fig. 11 shows the absorbance values determined by WST 1 assay for Saos-2 osteoblastic cell proliferation on chitosan/diatomite membranes. Results showed that diatomite incorporation increased cell proliferation on membrane surface. Cell proliferation on chitosan/diatomite composites were found to be significantly higher than that on the neat chitosan membrane. Diatomite incorporation to chitosan polymer matrix significantly enhances the osteoblast-like cell proliferation on membrane surface. Proliferation increase on $10 \%$ diatomite loaded composite membrane was found to be statistically significant for 7th and 10th day of incubation when compared to chitosan membrane. For 14th day, both $3 \%$ and $10 \%$ diatomite loaded groups proliferation increase was found to be statistically significant.

Flourescence imaging was performed to investigate the cell attachment on the diatomite embedded surface. Saos- 2 cells cultured on chitosan and chitosan/composite membranes for 7 days were stained with dapi/phalloidin and visualized by florescence microscopy (Figs. 12 and 13). Florescence images showed that number of Saos-2 cells attached and spread on composite membranes are significantly higher than that on chitosan membrane.

Table 3

Swelling \% of chitosan/diatomite composite membranes with increasing diatomite particle content.

\begin{tabular}{lll}
\hline Membrane groups & Swelling $\% 1 \mathrm{~h}$ & Swelling \% $24 \mathrm{~h}$ \\
\hline Chitosan & $165 \pm 0,1$ & $162 \pm 0,1$ \\
1\% Diatomite & $213 \pm 0,12$ & $163 \pm 0,1$ \\
3\% Diatomite & $207 \pm 0,69$ & $179 \pm 0,29$ \\
$5 \%$ Diatomite & $356 \pm 0,21$ & $323 \pm 0,81$ \\
10\% Diatomite & $209 \pm 0,11$ & $205 \pm 0,13$
\end{tabular}

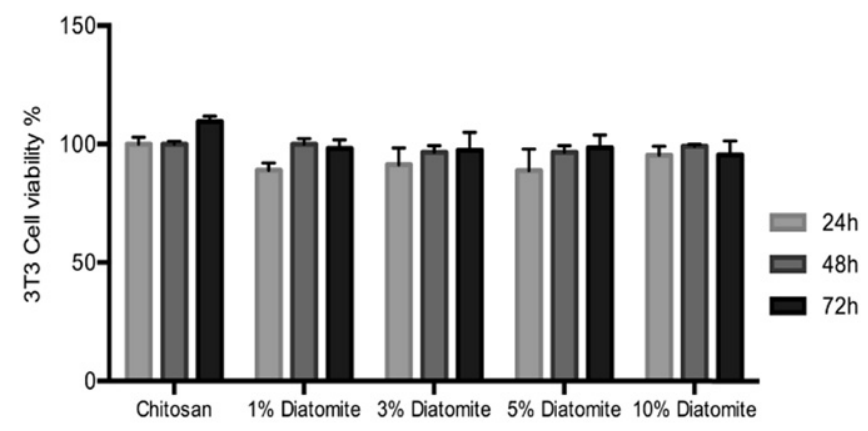

(a)

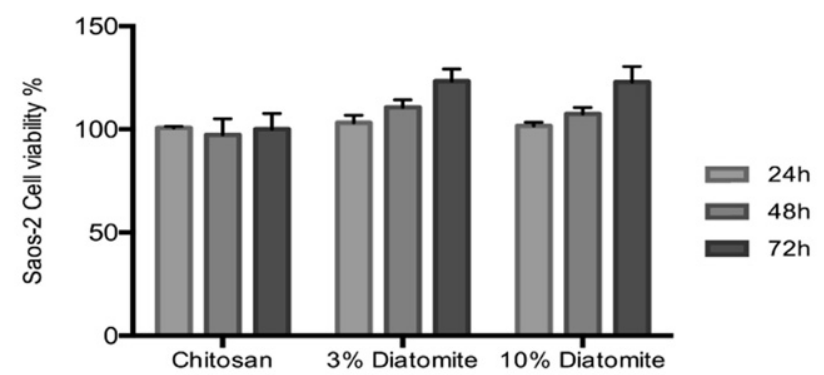

(b)

Fig. 10. In vitro cytotoxicity results of chitosan/diatomite composite membranes on 3T3 cell line (a) and Saos-2 cell line (b).

Microscopic observations revealed that Saos- 2 cells were attached on surface and spread on chitosan-diatomite membrane. Phalloidin stained cytoplasmic extensions of Saos-2 cells shown in Fig. 12 indicated that Saos- 2 cells presented a well-spread morphology and interaction with surface and each other on diatomite loaded membranes (Fig. 13).

Osteoblast material interaction depends on the surface aspects of materials which can be defined regarding their topography, chemistry or surface energy. These surface characteristics determine the adsorption of biological molecules to the material surface and the orientation of adsorbed molecules [43]. Defining these topographic parameters has an influence on cell-biomaterial adhesion, by improving cell attachment and spreading [44] Fig. 12 also shows that Saos-2 cells spread around the diatomite particles on the chitosan membrane surface.

\subsubsection{Alkaline phosphatase activity}

The ALP activity of composite membranes was evaluated for 7 and 21 day incubation periods. Fig. 14 shows the ALP concentration obtained from Saos-2 cultures on membranes. Results showed that diatomite particles with $3 \%(w / w)$ increased the ALP actitivty of cells compared to chitosan membrane at 21th day of incubation. All groups showed

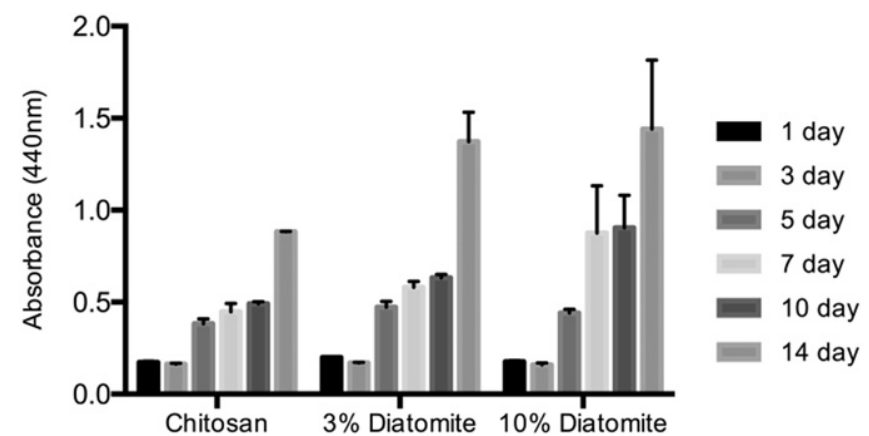

Fig. 11. Saos-2 proliferation on chitosan/POSS composite membranes. 

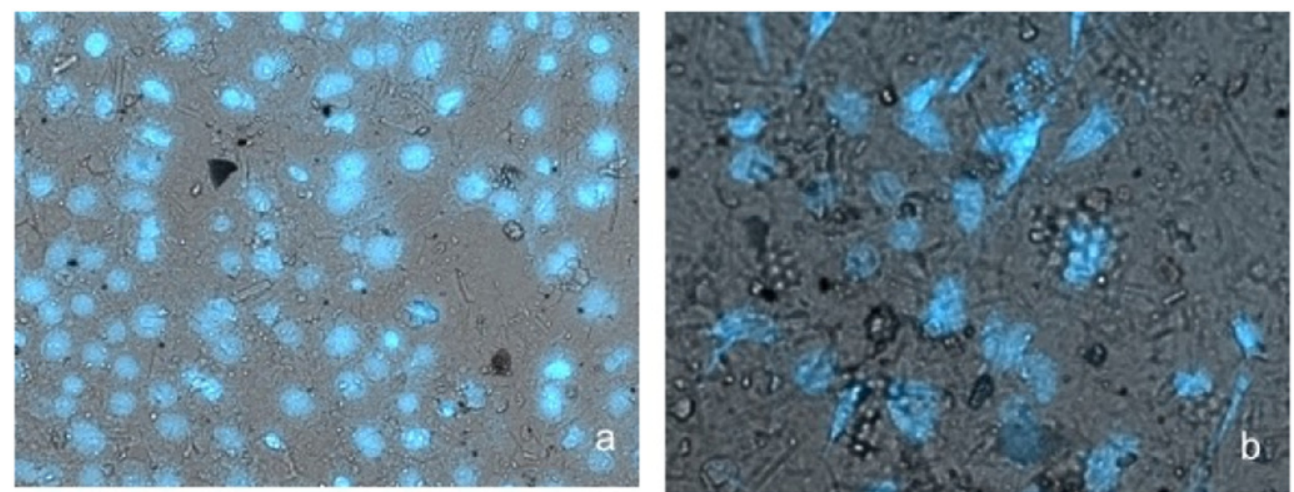

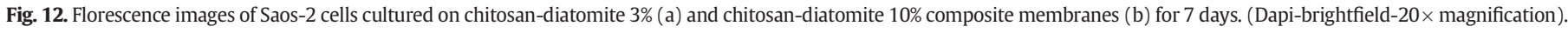
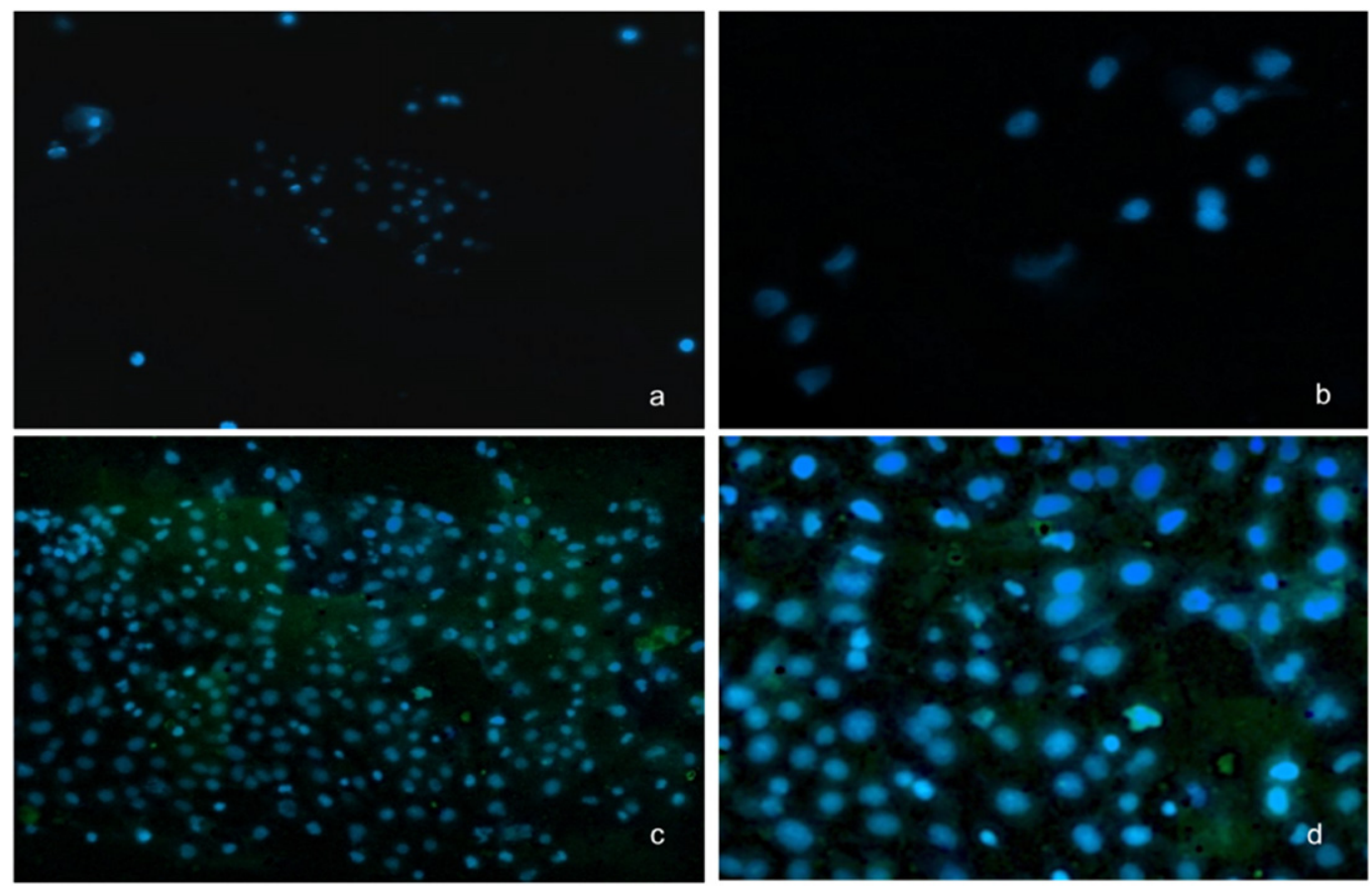

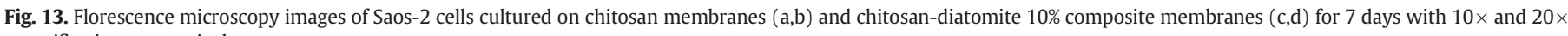
magnifications respectively.

statistically significant ALP activity differences for 7th ad 21th day incubation periods $(\mathrm{p}<\mid 0.05)$.

\section{Conclusions}

In this study, diatomite particles with their unique structure and favorable properties were used as ideal candidates for hard tissue regeneration applications. NOovel chitosan-diatomite composite membranes were prepared with solvent casting technique. AFM, FTIR, Protein adsorption, contact angle analyses and mechanical tests were applied to investigate the effects of diatomite loading on physical and chemical properties of composite membranes. Results of this study showed that diatomite incorporation improved the improved the surface area and roughness, swelling properties, and protein adsorption capacities of chitosan membranes which are important factors for osteoblast adhesion and proliferation. Furthermore, cytotoxicity results revealed that chitosan/diatomite composite membranes showed no cytotoxic effect on 3T3 and Saos-2 cell lines and possessed good biocompatibility. In vitro cell culture studies indicated that diatomite incorporation increased osteoblastic Saos-2 cell spreading and proliferation on membranes. In addition, ALP activity of Saos-2 cells increased remarkably for 7 and 21 day incubation periods for $3 \mathrm{wt} \%$ diatomite loaded samples. In conclusion, chitosan membranes reinforced with diatomite particles would constitute a novel and desirable composite biomaterial with its enhanced properties and high biological activity for bone tissue engineering applications.

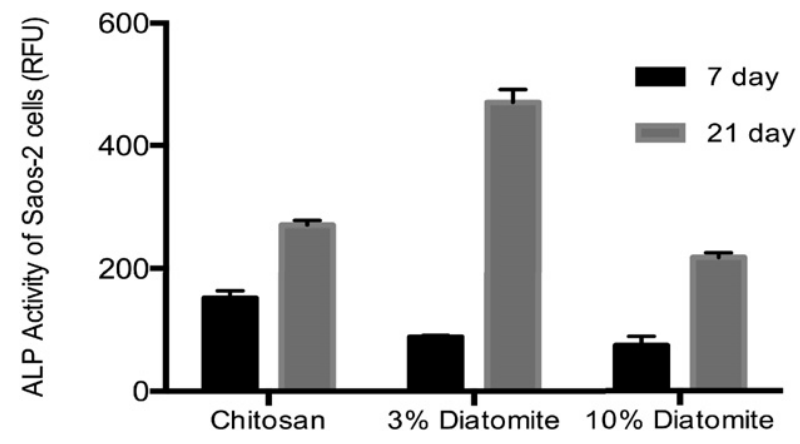

Fig. 14. ALP activity of Saos-2 cells cultured on chitosan/diatomite composite membranes for 7 and 21 days. 


\section{Acknowledgments}

This study was supported by the Scientific Research Project of Izmir Institute of Technology (No. 2011 IYYTE02). The authors thank to Assist Prof. Dr. Meltem Alper from Aksaray University supplying SaOS-2 cell line. The authors are also grateful to Izmir Institute of Technology (Iztech) Biotechnology and Bioengineering Research and Application Center for fluorescence microscopy analyses.

\section{References}

[1] C.F. Meunier, P. Dandoy, B.L. Su, Encapsulation of cells within silica matrixes: towards a new advance in the conception of living hybrid materials, J. Colloid Interface Sci. 342 (2) (2010) 211-224.

[2] C.J. Wu, A.K. Gaharwar, P.J. Schexnailder, G. Schmidt, Development of biomedica polymer-silicate nanocomposites: a materials science perspective, Materials 3 (5) (2010) 2986-3005.

[3] A. El Yacoubi, A. Massit, M. Fathi, B.C. El Idrissi, K. Yamni, Characterization of siliconsubstituted hydroxyapatite powders synthesized by a wet precipitation method, IOSR J. Appl. Chem. 7 (11) (2014) 24-29.

[4] T.D.H. Le, W. Bonani, G. Speranza, V. Sglavo, R. Ceccato, D. Maniglio, ... C. Migliaresi, Processing and characterization of diatom nanoparticles and microparticles as potential source of silicon for bone tissue engineering, Mater. Sci. Eng. C 59 (2016) 471-479.

[5] A. Tautzenberger, A. Kovtun, A. Ignatius, Nanoparticles and their potential for application in bone, Int. J. Nanomedicine 7 (2012) 4545-4557.

[6] K. Grandfield, I. Zhitomirsky, Electrophoretic deposition of composite hydroxyapatite-silica-chitosan coatings, Mater. Charact. 59 (1) (2008) 61-67.

[7] K. Madhumathi, P.T. Sudheesh Kumar, K.C. Kavya, T. Furuike, H. Tamura, S.V. Nair, R Jayakumar, Novel chitin/nanosilica composite scaffolds for bone tissue engineering applications, Int. J. Biol. Macromol. 45 (2009) 289-292.

[8] V. Puchol, J. El Haskouri, J. Latorre, C. Guillem, A. Beltrán, D. Beltrán, P. Amorós, Biomimetic chitosan-mediated synthesis in heterogeneous phase of bulk and mesoporous silica nanoparticles, Chem. Commun. 19 (2009) 2694-2696.

[9] Y. Shirosaki, T. Okayama, K. Tsuru, S. Hayakawa, A. Osaka, Synthesis and cytocompatibility of porous chitosan-silicate hybrids for tissue engineering scaffold application, Chem. Eng. J. 137 (1) (2008) 122-128.

[10] B.P. Nair, D. Gangadharan, N. Mohan, B. Sumathi, P.D. Nair, Hybrid scaffold bearing polymer-siloxane Schiff base linkage for bone tissue engineering, Mater. Sci. Eng. C 52 (2015) 333-342.

[11] O. Şan, R. Gören, C. Özgür, Purification of diatomite powder by acid leaching for use in fabrication of porous ceramics, Int. J. Miner. Process. 93 (1) (2009) 6-10.

[12] Y. Wang, J. Cai, Y. Jiang, X. Jiang, D. Zhang, Preparation of biosilica structures from frustules of diatoms and their applications: current state and perspectives, Appl. Microbiol. Biotechnol. 97 (2) (2013) 453-460.

[13] R. Gordon, D. Losic, M.A. Tiffany, S.S. Nagy, F.A. Sterrenburg, The glass menagerie: diatoms for novel applications in nanotechnology, Trends Biotechnol. 27 (2) (2009) $116-127$.

[14] N. Ediz, İ. Bentli, İ. Tatar, Improvement in filtration characteristics of diatomite by calcination, Int. J. Miner. Process. 94 (3) (2010) 129-134.

[15] H.E.G.M.M. Bakr, Diatomite: its characterization, modifications and applications, Asian journal of materials science 2 (3) (2010) 121-136.

[16] B. Gao, P. Jiang, F. An, S. Zhao, Z. Ge, Studies on the surface modification of diatomite with polyethyleneimine and trapping effect of the modified diatomite for phenol Appl. Surf. Sci. 250 (1) (2005) 273-279.

[17] M.A. Al-Ghouti, M.A.M. Khraisheh, S.J. Allen, M.N. Ahmad, The removal of dyes from textile wastewater: a study of the physical characteristics and adsorption mechanisms of diatomaceous earth, J. Environ. Manag. 69 (3) (2003) 229-238.

[18] M.A.M. Khraisheh, M.A. Al-Ghouti, S.J. Allen, M.N. Ahmad, Effect of $\mathrm{OH}$ and silanol groups in the removal of dyes from aqueous solution using diatomite, Water Res. 39 (2005) (2005) 922-932.

[19] S.R. Cicco, D. Vona, E. De Giglio, S. Cometa, M. Mattioli-Belmonte, F. Palumbo, G.M Farinola, Chemically modified diatoms biosilica for bone cell growth with combined drug-delivery and antioxidant properties, ChemPlusChem 80 (7) (2015) 1104-1112.

[20] K.M. Wee, T.N. Rogers, B.S. Altan, S.A. Hackney, C. Hamm, Engineering and medical applications of diatoms.Journal of, Nanosci. Nanotechnol. 5 (1) (2005) 88-91.

[21] M.S. Aw, S. Simovic, Y. Yu, J. Addai-Mensah, D. Losic, Porous silica microshells from diatoms as biocarrier for drug delivery applications, Powder Technol. 223 (2012) 52-58.

[22] M. Lopez-Alvarez, E.L. Solla, P. González, J. Serra, B. Leon, A.P. Marques, R.L. Reis, Silicon-hydroxyapatite bioactive coatings ( $\mathrm{Si}-\mathrm{HA}$ ) from diatomaceous earth and silica. Study of adhesion and proliferation of osteoblast-like cells, J. Mater. Sci. Mater. Med. 20 (5) (2009) 1131-1136.

[23] A. Hertz, V. FitzGerald, E. Pignotti, J.C. Knowles, T. Sen, I.J. Bruce, Preparation and characterisation of porous silica and silica/titania monoliths for potential use in bone replacement, Microporous Mesoporous Mater. 156 (2012) 51-61.

[24] X. Bao, A. Teramoto, K. Abe, Carboxymethyl chitosan nonwoven scaffold for bone regeneration, Key Eng. Mater. 464 (2011) 712-716.

[25] S.I. Park, M.A. Daeschel, Y. Zhao, Functional properties of antimicrobial lysozymechitosan composite films, J. Food Sci. 69 (8) (2004) M215-M221.

[26] A. Di Martino, M. Sittinger, M.V. Risbud, Chitosan: a versatile biopolymer for orthopaedic tissue-engineering, Biomaterials 26 (30) (2005) 5983-5990.

[27] A.B. Dhanikula, R. Panchagnula, Development and characterization of biodegradable chitosan films for local delivery of paclitaxel, AAPS J. 6 (3) (2004) 88-99.

[28] V.P. Hoven, V. Tangpasuthadol, Y. Angkitpaiboon, N. Vallapa, S. Kiatkamjornwong, Surface-charged chitosan: preparation and protein adsorption, Carbohydr. Polym. 68 (2007) 44-53.

[29] W. Hsieh, C. Chang, S. Lin, Morphology and characterization of 3D micro-porous structured chitosan scaffolds for tissue engineering, Colloids Surf. B: Biointerfaces 57 (2007) 250-255.

[30] Terry L. Riss, Richard A. Moravec, Andrew L. Niles, Helene A. Benink, Tracy J. Worzella, Lisa Minor, Cell Viability Assays-Assay Guidance Manual. (2013).

[31] A.M. Lipski, C.J. Pino, F.R. Haselton, I.W. Chen, V.P. Shastri, The effect of silica nanoparticle-modified surfaces on cell morphology, cytoskeletal organization and function, Biomaterials 29 (28) (2008) 3836-3846.

[32] F. Noll, M. Sumper, N. Hampp, Nanostructure of diatom silica surfaces and of biomimetic analogues, Nano Lett. 2 (2) (2002) 91-95.

[33] A.R. Costa-Pinto, R.L. Reis, N.M. Neves, Scaffolds based bone tissue engineering: the role of chitosan, Tissue Eng. B Rev. 17 (5) (2011) 331-347; F. Croisier, C. Jérôme, Chitosan-based biomaterials for tissue engineering, Eur. Polym. J. 49 (4) (2013) 780-792

[34] N. Faucheux, R. Schweiss, K. Lützow, C. Werner, T. Groth, Self-assembled monolayers with different terminating groups as model substrates for cell adhesion studies, Biomaterials 25 (14) (2004) 2721-2730.

[35] R. Tzoneva, N. Faucheux, T. Groth, Wettability of substrata controls cell-substrate and cell-cell adhesions, Biochimica et Biophysica Acta (BBA)-General Subjects 1770 (11) (2007) 1538-1547.

[36] K.L. Menzies, L. Jones, The impact of contact angle on the biocompatibility of biomaterials, Optom. Vis. Sci. 87 (6) (2010) 387-399.

[37] R.A. Latour, Biomaterials: protein-surface interactions, Encyclopedia of biomaterials and biomedical engineering 1 (2005) 270-278.

[38] P. Yuan, D.O. Wu, H.P. He, Z.Y. Lin, The hydroxyl species and acid sites on diatomite surface: a combined IR and Raman study, Appl. Surf. Sci. 227 (1) (2004) 30-39.

[39] F. Al-Sagheer, S. Muslim, Thermal and mechanical properties of chitosan $/ \mathrm{SiO}_{2}$ hybrid composites, J. Nanomater. 2010 (2010) 3.

[40] S. Mendioroz, M.J. Belzunce, J.A. Pajares, Thermogravimetric study of diatomites, J. Therm. Anal. 35 (7) (1989) 2097-2104.

[41] X. Wu, Y. Sun, W. Xie, Y. Liu, X. Song, Development of novel dental nanocomposites reinforced with polyhedral oligomeric silsesquioxane (POSS), Dent. Mater. 26 (2009) 456-462.

[42] K. Li, H. Sun, H. Sui, Y. Zhang, H. Liang, X. Wu, Q. Zhao, Composite mesoporous silica nanoparticle/chitosan nanofibers for bone tissue engineering, RSC Adv. 5 (23) (2015) 17541-17549.

[43] K. Anselme, Osteoblast adhesion on biomaterials, Biomaterials 21 (7) (2000) 667-681.

[44] S.C. Rizzi, D.J. Heath, A.G.A. Coombes, N. Bock, M. Textor, S. Downes, Biodegradable polymer/hydroxyapatite composites: surface analysis and initial attachment of human osteoblasts, J. Biomed. Mater. Res. 55 (4) (2001) 475-486. 